\title{
Numerical investigation of welding residual stresses in planar bridge trusses made of CHS steel profiles
}

\author{
F. Zamiri \& A. Nussbaumer \& C. Acevedo \\ École Polytechnique Fédérale de Lausanne (EPFL), Lausanne, Switzerland
}

\begin{abstract}
The weld-induced residual stresses in a tubular planar K-shaped connection made of construction steel grades $\mathrm{S} 355 \mathrm{~J} 2 \mathrm{H}$ and $\mathrm{S} 690 \mathrm{QH}$ is evaluated using three-dimensional finite element models in thermomechanical simulation of welding process. Both lumped single-pass and multi-pass simulation alternatives are examined.

The transversal component is the largest residual stress component at the gap region for all models, with values reaching the yield strength of studied steel grades. The shapes of residual stress profiles evaluated from the multi-pass models for the two steel grades show a similar trend. Although this can change when the effects of phase transformations will be considered. Considerable difference in the residual stress distribution in the gap region is observed between multi-pass welding simulation and equivalent single-pass models for both steel grades studied. For the single-pass models, the effect of using element activation on the residual stresses are negligible.
\end{abstract}

\section{INTRODUCTION}

Application of circular hollow sections for bridge structures has increased since the early 90's, especially in Europe (Acevedo and Nussbaumer 2012). Tubular bridges provide aesthetics, structural efficiency, and sustainability and are advantageous compared to other structural solutions, in particular for mid-sized span bridges (Nussbaumer et al. 2010). Similar to the offshore platform structures, two fabrication methods for the tubular bridge joints exist: welding the tubes together, and using cast steel parts in place of joints and connecting them to truss members by girth welds. While the latter has shown a better fatigue performance in the past, the former fabrication method is still interesting for some bridge projects because of cost and aesthetics issues.

Using high-strength low-alloy (HSLA) steels can lead to a more transparent structure with a higher live load to dead load ratio. Part 1-12 of Eurocode 3 which was introduced in 2007 permits the use of steel

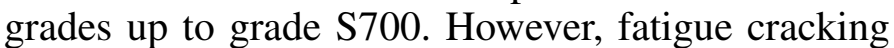
in the welded joints is a limiting factor for application of higher grade steels in tubular bridge structures. In the current IIW recommendations (Hobbacher 2003) fatigue life is considered the same for the structural steels up to grade S960. Part 1-9 of Eurocode (EN1993 2005a) recommends the use of the same fatigue resistance curves for all structural steel grades. Although experimental fatigue data supports the above fact, the underlying phenomena of evolution of microstructure in the heat affected zone and formation of residual stresses during the welding process are different for various steel grades.

Residual stresses in the HAZ are one of the major factors that influence the fatigue crack growth, and hence, the fatigue life of the welded details (Radaj 2003). The tensile residual stresses affect the fatigue response of the detail by keeping the cracks open, even if the external load is compressive. The nonuniform plastic deformations which occur during the welding are the main source for the formation of welding residual stresses (Withers 2007). Several factors affect the residual stress magnitude and distribution in the HAZ, including:

- geometry

- material properties

- mechanical restraints of the connection

- temperature history experienced by the weldment

The temperature history mentioned above is determined by several welding parameters, namely heat input, shape of the heat source and the number of welding passes. 


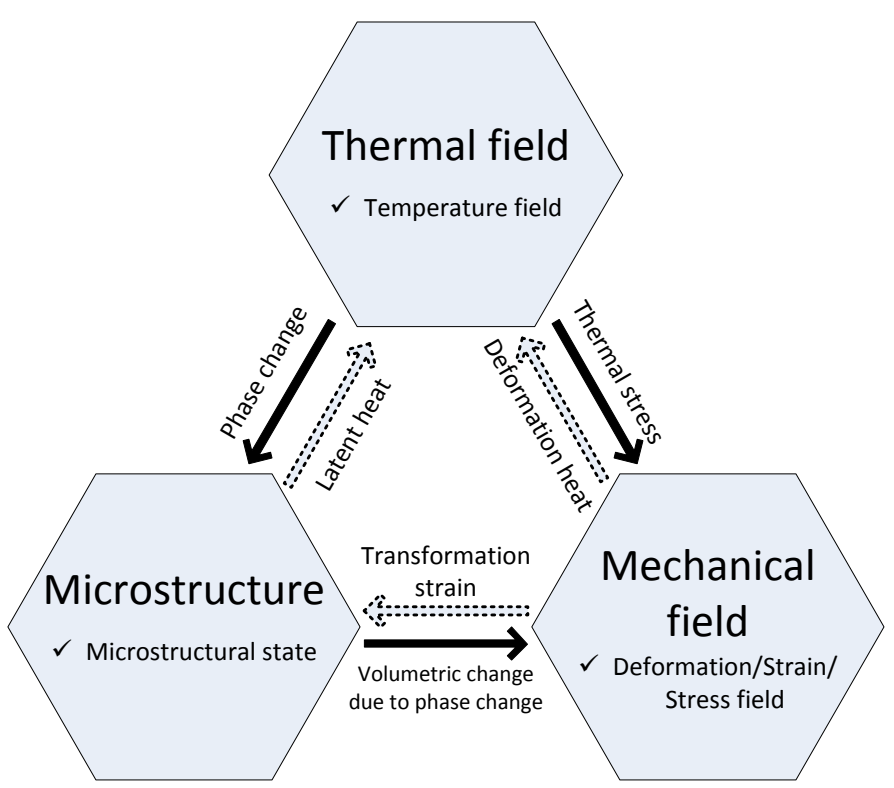

Figure 1: Simplification of interactions between the three domains during the welding process. Dark arrows show the dominant interactions.

During the welding process many different phenomena occur which can be regrouped into three interacting domains: thermal field, mechanical field, and microstructure field. Figure 1 shows these three domains with the simplified interactions that take place during welding. The dark arrows depict the dominating effects and the dotted arrows indicate that the corresponding effect is of less importance. The thermal field affects both the microstructure and the mechanical field, while the inverse effects are negligible. This is the key to de-coupling of the thermo-mechanical analysis into a sequential procedure which includes solving the thermal field problem, and subsequently solving each of the microstructure and mechanical fields.

\section{NUMERICAL SIMULATION}

The geometry for the planar K-joint modeled in this study is similar to the joints of full-scale specimens which were tested under constant amplitude fatigue loading in ICOM laboratory (Acevedo \& Nussbaumer 2012). The dimensions and non-dimensional geometric parameters of the joint are shown in Table 1. The dimensions are exemplar of tubular bridge trusses in which the value of $\gamma$ is below the application range of CIDECT (2000) formulas for the stress concentration factors (application range is $12 \leq \gamma \leq 30$ ). The CIDECT's stress concentration factors are given for the case that no eccentricity exists in the joint, which is not the case for many bridge joints, including the joint investigated here.

The detail of weld gap at the crown toe and the crown heel is presented in figure 2 . The welding was done in 7 welding passes, according to the welding procedure specifications from the fabricator. As will be seen later, the number of weld passes was reduced for the numerical analysis. The complex weld geome-

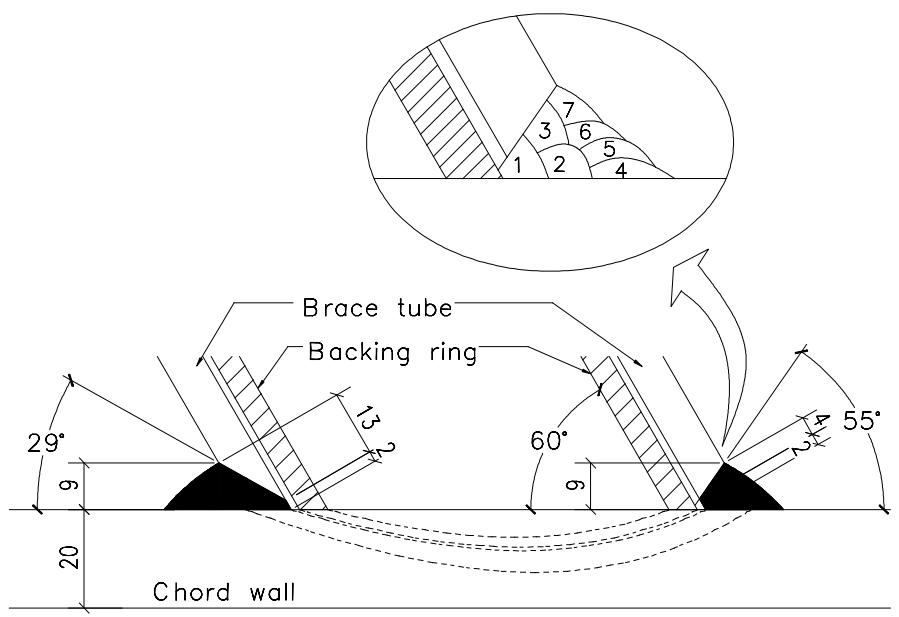

Figure 2: Geometry of the weld gap for the brace-to-chord connection. The detail shows the welding passes according to the welding procedure specifications.

try was simulated according to the method explained by (Costa Borges 2008). The arc welding was done using flux cored electrodes. The steel backing ring provides more complete weld penetration and hence, a better fatigue performance (Schumacher \& Nussbaumer 2006). However, it does not have a significant effect on the thermal or mechanical field for welding simulation. Therefore, it was not included in the model.

\subsection{Material data}

The original truss was made of structural steel S355J2H according to EN:10210-1 2006. To evaluate the effect of material, simulation was carried out with both steel grade S355J2H and grade S690QH. the temperature dependent thermal and mechanical properties were chosen from different sources. The values suggested by Eurocode 3-1-2 fire design recommendations (2005b) were used for the thermal conductivity, specific heat capacity, and latent heat of the steel material. Temperature-dependent Young's modulus values were selected according to Eurocode. Poisson's ratio and coefficient of thermal expansion were chosen as suggested by (Michaleris 2011). For yield strength of S355 steel, the values given by Michaleris were used. Yield strength of S690 was selected from Eurocode values. The rate-independent mechanical properties of the two steel grades are given in Figure 3. The same material properties are assumed for the parent metal and weld material. Transformation plasticity is not considered in this study.

Table 1: Profile sizes and non-dimensional geometric parameters of the studied K-Joint

\begin{tabular}{lcllc}
\multicolumn{2}{l}{ Nominal dimensions } & & \multicolumn{2}{l}{ Non dimensional parameters } \\
\cline { 1 - 1 } Chord & $168.3 \times 20 \mathrm{~mm}$ & & $\beta\left(d_{1} / d_{0}\right)$ & 0.53 \\
Brace & $88.9 \times 8 \mathrm{~mm}$ & & $\gamma\left(d_{0} / 2 t_{0}\right)$ & 4.21 \\
Eccentricity(e) & $49.3 \mathrm{~mm}$ & & $e / d_{0}$ & 0.29 \\
$\theta^{*}$ & $60^{\circ}$ & & $\tau\left(t_{1} / t_{0}\right)$ & 0.4 \\
\hline
\end{tabular}

* Nominal angle between the chord and the braces. 

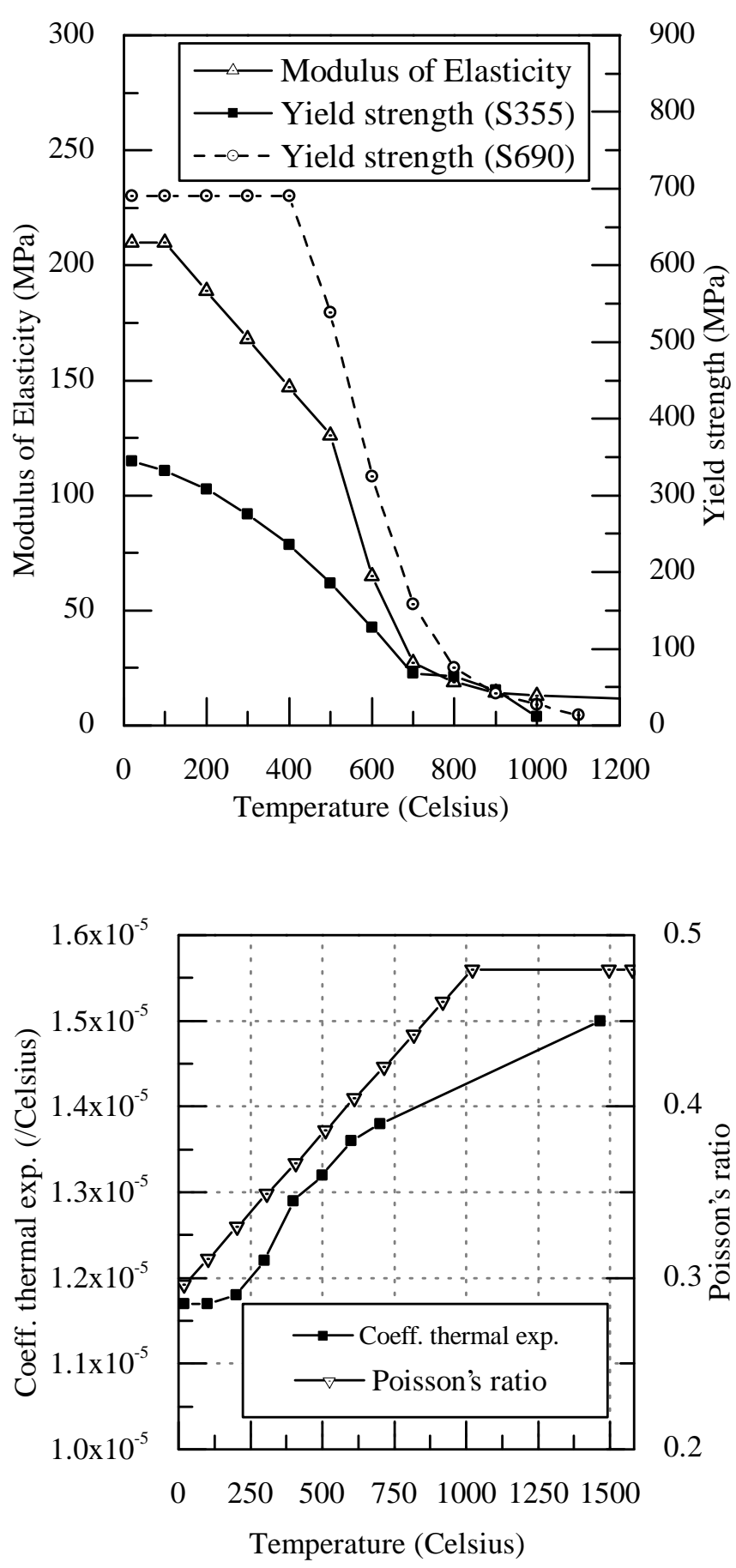

Figure 3: (Top) Change of $E$ and $\sigma_{y}$ with temperature for $\mathrm{S} 355$ and S690 steels (Michaleris 2011, EN1993 2005b); (Bottom) Temperature dependent $\nu$ and $\alpha$ for the same steel grades (Michaleris 2011).

\subsection{Heat source and boundary conditions}

There are several heat source models available in the literature (Radaj 2003) to model the welding torch. Although the double ellipsoid model (Goldak \& Akhlaghi 2005) is the most desirable model for the modeling of arc welding process, its calibration requires considerable data in terms of registered welding temperature history. In this stage of study, a simple model, as recommended in MORFEO (2011), was employed. The weld torch specifications are presented in Table 2 . The selected volumetric heat source
Table 2: Arc welding parameters used in modeling of heat source

\begin{tabular}{lr}
\hline Parameter & Value \\
\hline Number of welding passes & 7 \\
Welding torch speed [mm/s] & 5.5 \\
Welding current [A] & 270 \\
Voltage [V] & 30 \\
Arc welding efficiency [\%] & 0.732 \\
Heat power input per pass [kW] & 5.93 \\
Total heat power input [kW] & 41.5 \\
\hline
\end{tabular}

shape was a cylinder with a linear heat input intensity distribution in the longitudinal direction of cylinder. The base radius and height of the cylinder for the single-pass weld model were selected as $15 \mathrm{~mm}$. The volume dimensions were calibrated according to the size of fusion zone. The cylindrical heat sources for the three passes of the multi-pass simulation were scaled down to fit into their corresponding weld beads whose shapes can be seen in Figure 5c.

The sequence for the welding of the two braces is shown in Figure 4. The welding for each brace started at the crown heel and finished at the crown toe on each side of the connection. Once one pass of all 4 weld parts were done, the next pass would start and so forth. The welding start and stop positions were selected according to the welding procedure used at the time of fabrication of the fatigue-tested specimens made of steel grade $\mathrm{S} 355 \mathrm{~J} 2 \mathrm{H}$. Although having the weld stop position at the crown toe can potentially accelerate the fatigue crack propagation, the fatigue tests did not show any significant deviation from the CIDECT fatigue strength curves (Acevedo \& Nussbaumer 2012), likely because of the high quality of welding workmanship. It is worth mentioning that the fabricator has recently revised its welding procedure to relocate the weld stops outside the crown toe region.

The seven weld passes were simplified in the analyses into either a lumped single pass or a lumped threepass weld. The total heat input was kept as the same value shown in Table 2 for all analyses, according to Radaj (2003). For the three-pass welding simulation, the heat power input for each of the three passes was one-third of the total heat power input given in Table 2 . The heat loss through convection and radiation was modeled by using a combination film coefficient in the model. Table 3 depicts the detailed time steps for the simulation of an equivalent single pass weld. for the three-pass weld, the same timing (i.e. 25 seconds for welding, followed by a 120 seconds cooling period, with a long cooling time step at the end of welding) was selected. A preheating temperature of $100^{\circ} \mathrm{C}$ was assumed for the three-pass welding simulation.

The deformation of the model was not restrained. to maintain the equilibrium, only the three translational displacement components were fixed at one end of the chord (right side). 
Table 3: Welding sequence for equivalent single-pass weld simulation. Weld part numbering is as shown in Figure 4

\begin{tabular}{lcc}
\hline Step name & $\begin{array}{c}\text { Start time } \\
\text { seconds }\end{array}$ & $\begin{array}{c}\text { End time } \\
\text { seconds }\end{array}$ \\
\hline Waiting & 0 & 24 \\
Welding, part 1 & 25 & 50 \\
Cooling & 51 & 174 \\
Welding, part 2 & 175 & 200 \\
Cooling & 201 & 324 \\
Welding, part 3 & 325 & 350 \\
Cooling & 351 & 474 \\
Welding, part 4 & 475 & 500 \\
Cooling & 501 & 9000 \\
\hline
\end{tabular}

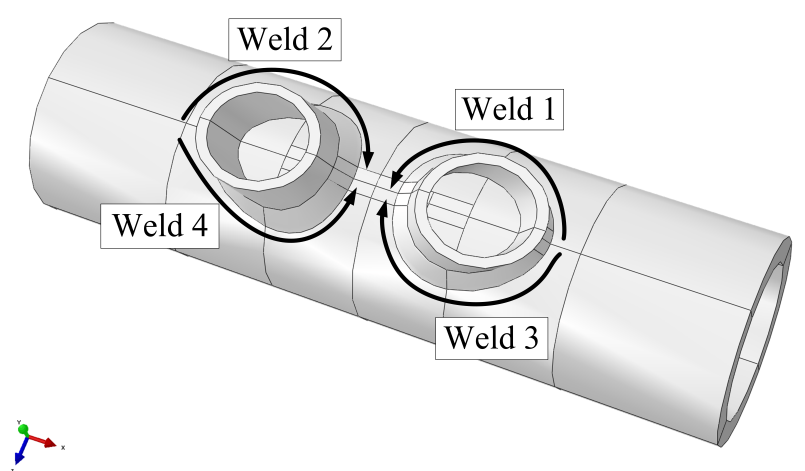

Figure 4: Welding sequence for the four weld parts of the K-joint connection.

\subsection{FE analysis details}

The analysis was carried out in MORFEO/Welding (2011) manufacturing simulation program. The model was created using 8-node linear isoparametric solid elements (Fig. 5a). It is known from the fatigue tests of the two full-scale specimens that the fatigue cracking first occurs at the hot spot located on the chord at the crown weld toe (the gap region between the two braces). Therefore, for the estimation of residual stress field, the mesh is refined in that location, with an element dimension of $1 \mathrm{~mm}$ to $2.2 \mathrm{~mm}$ (Fig. $5 b$ and $c)$.

In order to simulate the weld metal deposition for the multi-pass welding, the element activation option of the MORFEO/Welding program is utilized. Of the two available methods, namely activation by analysis time and activation by temperature, the former is chosen. In the temperature activation method, the elements are activated once the temperature reaches a threshold value (melting point). The method can result in some isolated elements which produce convergence problems during analysis. In the time-based element activation, a moving box passes along the weld trajectory with a user-defined speed. Once an element is within the box, the element will be activated. The effect of material deposition on the thermal solution is negligible, but it has significant impact on the mechanical solution. Therefore, the element activation was only used for the mechanical part of the problem.

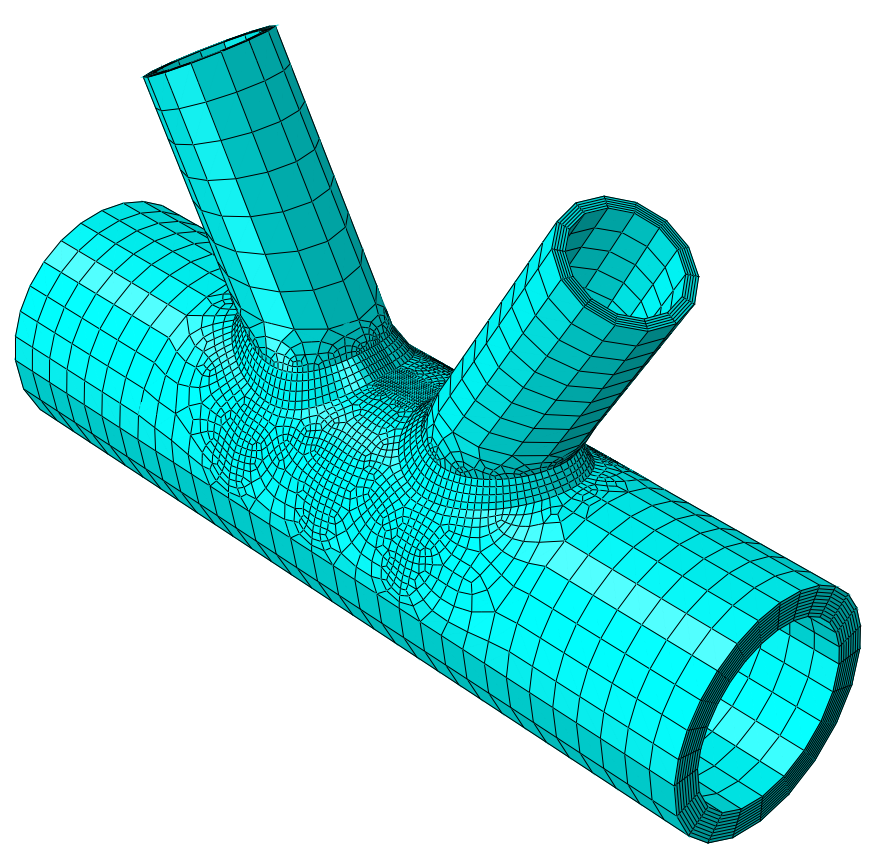

(a)

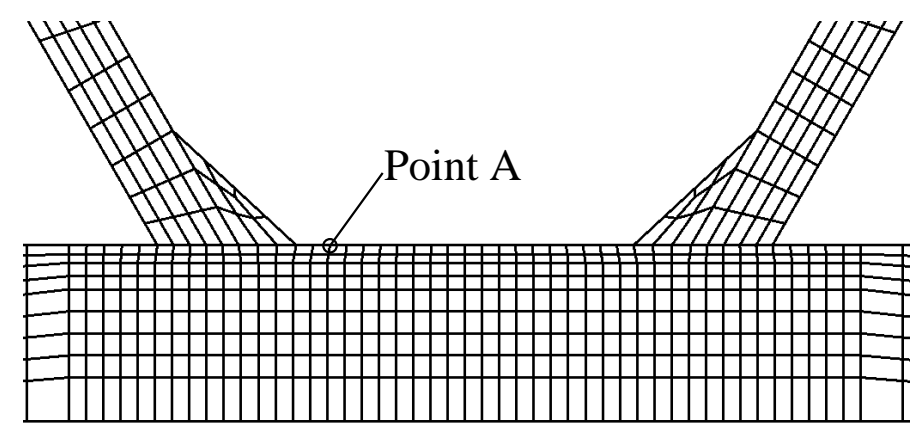

(b)

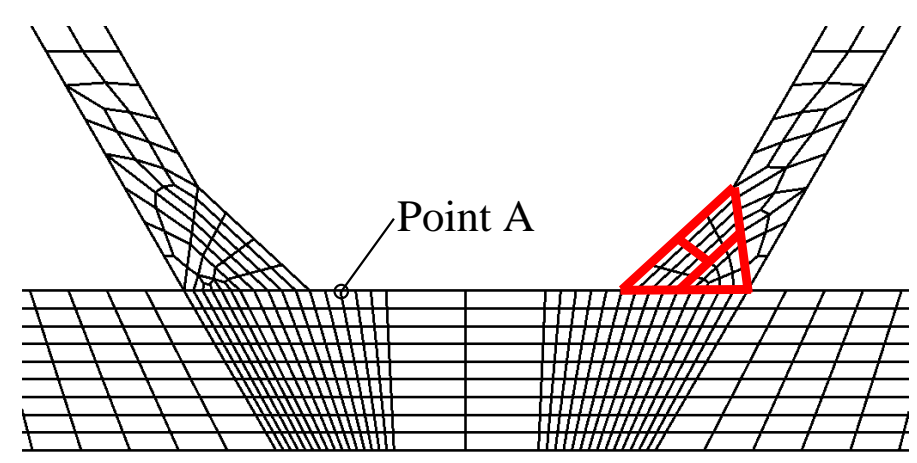

(c)

Figure 5: Finite element meshes used in analyses; (a)Overview; (b)Detail of the mesh at the gap region for the single-pass weld models; (c)Detail of the mesh and partitioning of the weld bead at the gap region for the multi-pass weld model. Point $\mathrm{A}$ is the point where the temperature history is evaluated.

\section{RESULTS}

\subsection{Thermal solution}

The temperature history at a node located on the chord surface in the gap region at $4 \mathrm{~mm}$ from the weld toe is 


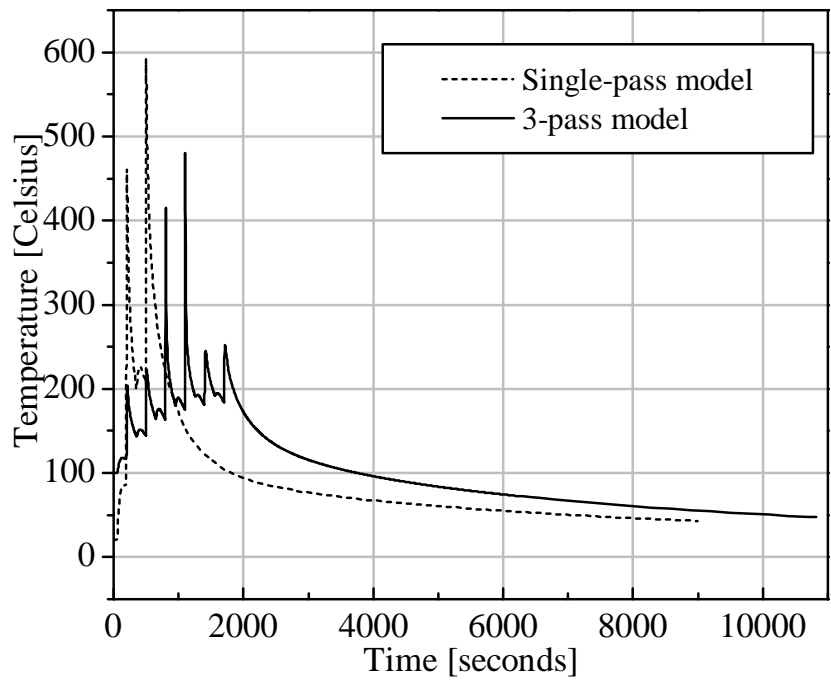

Figure 6: Calculated temperature time history for the single-pass and multi-pass simulations.

reported on Figure 6 for the two types of the models (the node location is shown in Figure 5b,c as Point A). It is recalled that the thermal analysis part was identical for the two steel types. As can be seen in the figure, the analysis was continued through the final cooling time until the temperature dropped below $50^{\circ} \mathrm{C}$. The two larger peaks observed for the single-path model correspond to the passage of the weld parts number 2 and 4 (see Figure 4) at the vicinity of the considered point. The calculated maximum temperature for the single-pass model is $23 \%$ higher than the peak temperature from the three-pass weld model. The reason being that the heat input in the latter model is more gradual which allows some cooling down between the welding operations.

\subsection{Mechanical solution}

As mentioned before, ongoing and previous fatigue experiments at ICOM have shown that the critical location for the fatigue cracking is at the crown toe location in the gap region. Cracking initiates at the HAZ but quickly goes into base metal and propagates there (Acevedo \& Nussbaumer 2012). The distributions of residual stresses in the gap region for the two studied steel grades are shown in Figures 7 and 8 for the case of the three-pass weld model. The transverse stress component is shown in Figures 7 and 8, which is the component perpendicular to the weld line. The figures show the presence of high tensile residual stresses in the gap region for both steel grades. The single-pass model with element activation showed a similar trend but with higher residual stresses at the middle of the gap region. This can be described by the higher calculated thermal strains due to the higher temperatures which was explained in the previous section.

Both models for S355J2H and S690QH predict low compressive transverse residual stresses at the location of weld roots (slightly dark regions in the loca-

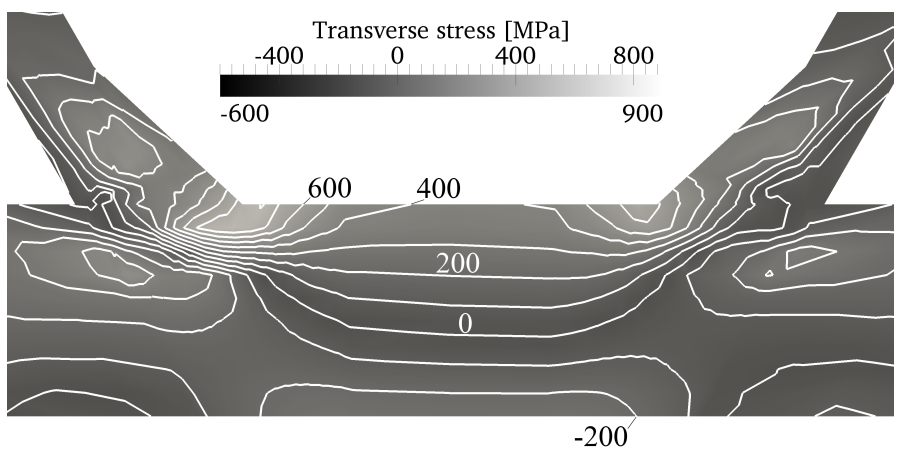

Figure 7: Distribution of the transverse stress component in the chord at gap region for steel S690QH (multi-pass weld simulation).

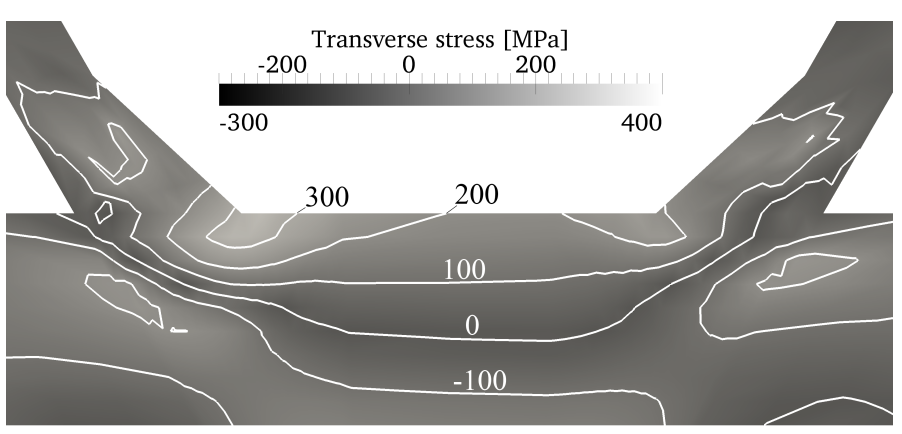

Figure 8: Distribution of the transverse stress component in the chord at gap region for steel $\mathrm{S} 355 \mathrm{~J} 2 \mathrm{H}$ (multi-pass weld simulation).

tions of weld roots). This is in agreement with the observation of no root cracking in the aforementioned fatigue tests which were conducted with $\mathrm{R}=0.1$ (thus likely diminishing the effect of stress range).

The through thickness profiles of three residual stress components at the left (dark lines) and right (gray lines) crown toes for the two steel grades $\mathrm{S} 355 \mathrm{~J} 2 \mathrm{H}$ and S690QH are presented in Figures 9 and 10. Comparing these profiles, a similar trend for the distribution of residual stresses between the two steel grades can be observed. However, this would not be the case when other modeling parameters such as volumetric changes due to phase transformations are taken into consideration.

As can be seen, the longitudinal component (i.e. the component tangent to the weld line) is less than the transverse component for all models. Considering the transversal component, all models indicate high residual stresses up to and even higher than the yield stress. The impact of the modeling method (singlepass versus multi-pass) is considerable for both steel grades, for which both peak value and peak locations are different between the two modeling methods. The difference is higher for the case of $\mathrm{S} 355 \mathrm{~J} 2 \mathrm{H}$ compared to the S690QH despite the fact that the two steel grades underwent identical temperature histories. The difference between models becomes less significant for the case of longitudinal and radial components of residual stresses. The radial stress profiles at the weld toe show that the radial stress component is not zero at the chord surface. Although the equilibrium of stresses implies that there should not be any radial residual stresses at the surface of the chord, but 


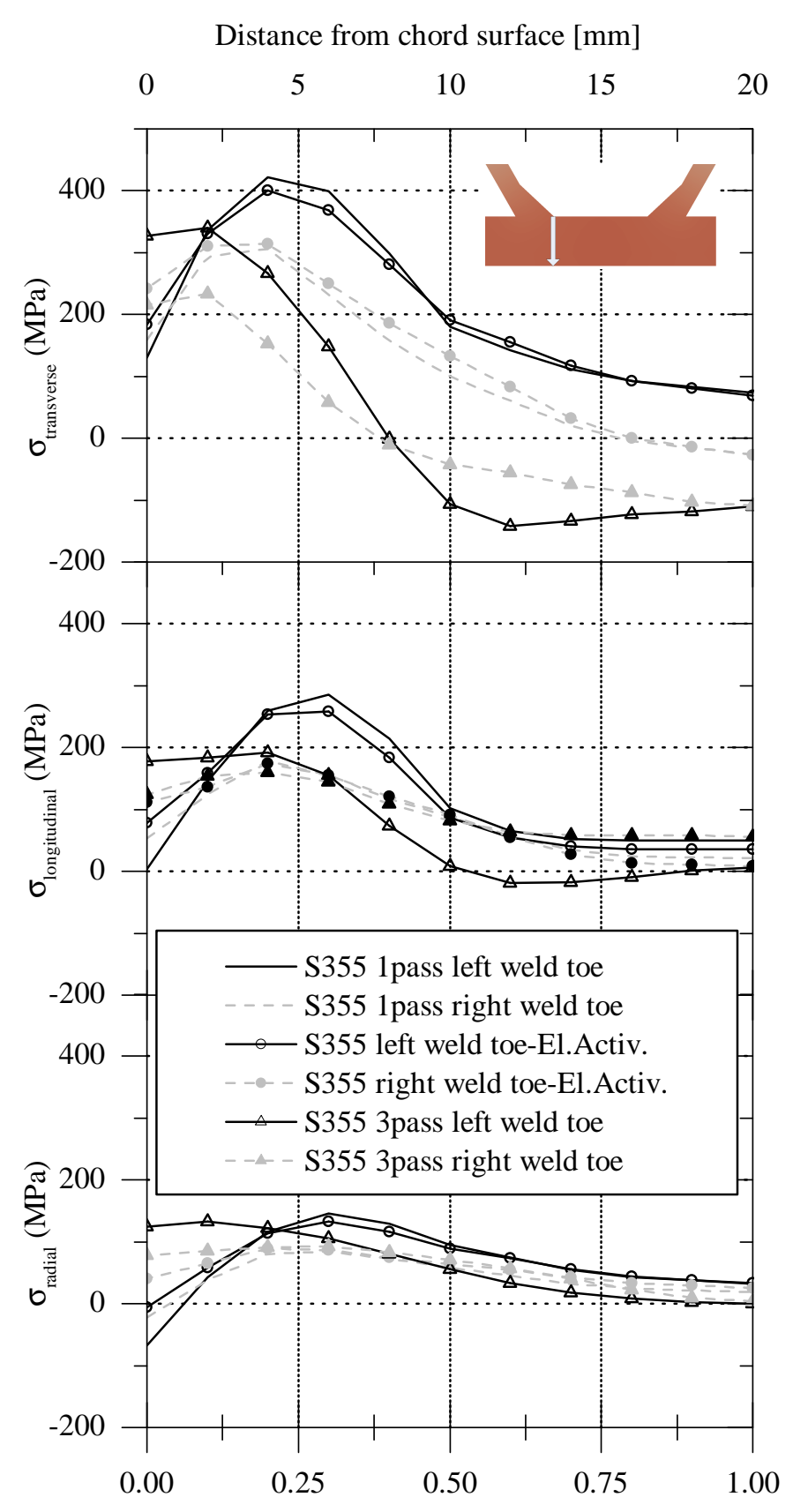

Normalized distance from chord surface

Figure 9: Through-thickness residual stress profiles at the weld toes (crown toe hot spot) for $\mathrm{S} 355 \mathrm{~J} 2 \mathrm{H}$.

this does not hold for the weld toe corner, where the resultant of residual stresses is not necessarily parallel to the chord surface. The evaluated tensile radial component at the surface from the multi-pass model is higher than the single-pass model. This shows that a triaxial residual stress state exists at the weld toe near the chord surface, with the largest component being the transversal component and the smallest component being the radial stress.

For both of the studied steel grades, the singlepass models predict a higher maximum value for the longitudinal residual stress component, compared to the three-pass models. However, the maximum value for the three-pass models occur in the chord surface, while the single-pass models report the maximum longitudinal stress to be at the depth of around $0.2 \mathrm{~T}$. Due to this difference in prediction of residual $\begin{array}{llll}0 & 5 & 10 & 15\end{array}$

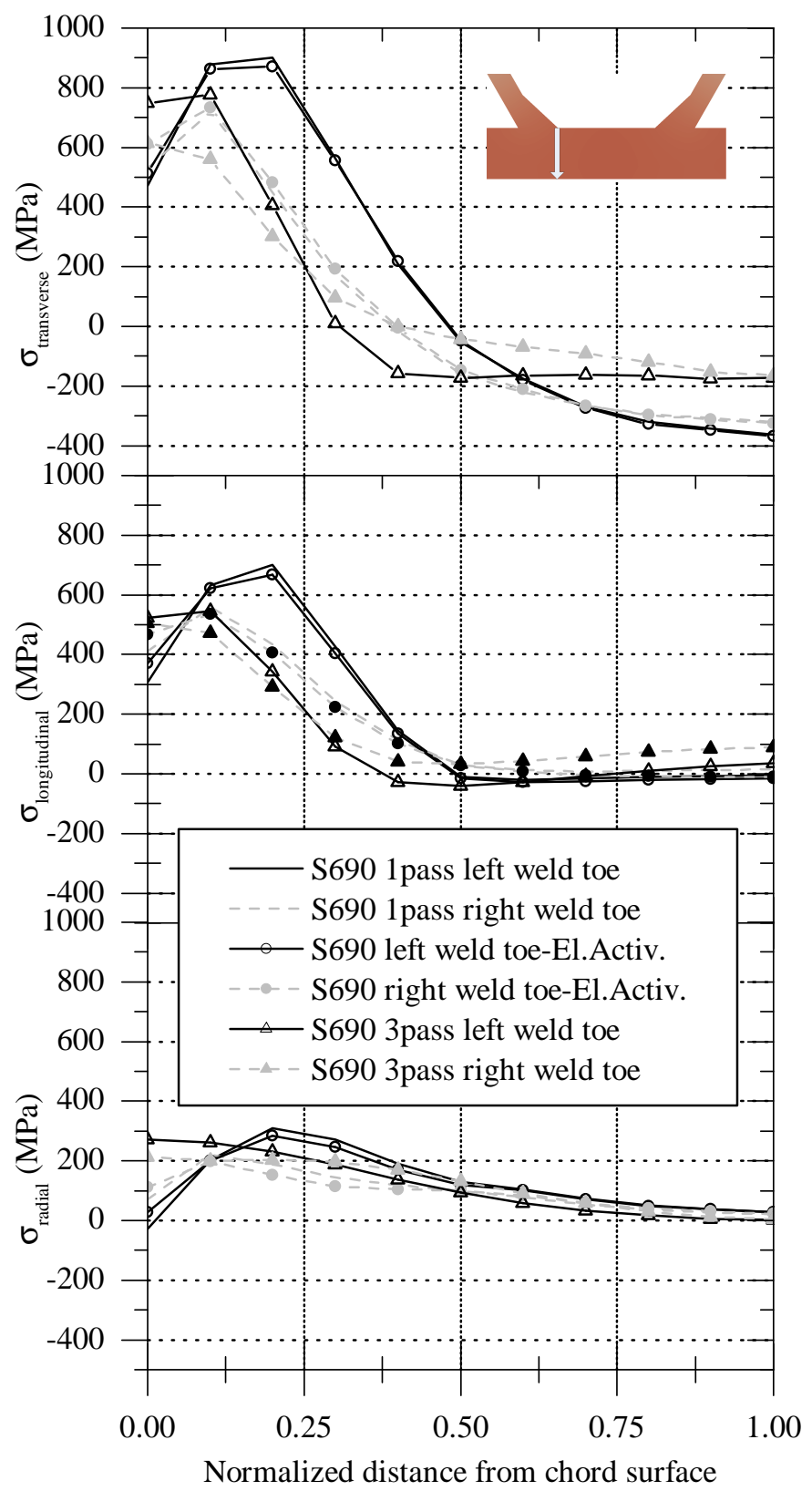

Figure 10: Through-thickness residual stress profiles at the weld toes (crown toe hot spot) for S690QH.

stresses, the prediction of fatigue life (and crack path) will be different in the subsequent crack propagation analyses, specially for the case that the joint undergoes compressive fatigue loading.

The asymmetry of the stress field can be observed by comparing the stress profiles at the right and left weld toes. However, the difference between the stress profiles at the two weld toes is reduced in the case of multi-pass welding simulation.

\section{CONCLUSION}

Thermo-mechanical welding analysis was utilized to evaluate welding residual stresses in a planar $\mathrm{K}$ shaped tubular joint for two grades of structural steel. The element activation analysis technique made no 
considerable difference for the equivalent single pass welding simulation; however, the results from multipass welding analysis showed considerable change in the distribution of residual stress field, specially for the case of transversal residual stresses.

For both of the steel grades studied, the transversal stress component in the gap region was the largest stress component, with the values at $f_{y}$. Also, the distribution of residual stresses calculated from multipass weld simulations show a similar trend. This conclusion should be taken with caution as volumetric changes due to phase transformation were not considered. Transformation plasticity will be implemented in future work.

\section{ACKNOWLEDGMENTS}

This research is part of the project P816 "Optimal use of hollow sections and cast nodes in bridge structures made of S355 and S690 steel", supervised by the Versuchsanstalt für Stahl, Holz und Steine at the Technische Universität Karlsruhe, which is supported financially and with academic advice by the Forschungsvereinigung Stahlanwendung e. V. (FOSTA), Düsseldorf, within the scope of the Stiftung Stahlanwendungsforschung, Essen.

\section{REFERENCES}

Acevedo, C. \& Nussbaumer, A. (2012). Effect of tensile residual stresses on fatigue crack growth and SN curves in tubular joints loaded in compression. International Journal of $\mathrm{Fa}$ tigue 36(1), 171-180.

Costa Borges, L. A. (2008). Size effects in the fatigue behaviour of tubular bridge joints (Thesis No. 4142). Ph. D. thesis, EPFL, Lausanne.

EN:10210-1 (2006). Hot finished structural hollow sections of non-alloy and fine grain steels. technical delivery requirements. European Standard.

EN1993 (2005a). Eurocode 3: Design of steel structures - Part 12:General rules - Structural fire design. Brussels: European Committee for Standardization.

EN1993 (2005b). Eurocode 3: Design of steel structures - Part 1-9: Fatigue. Brussels: European Committee for Standardization.

EN1993 (2007). Eurocode 3: Design of steel structures - Part 112:General - High strength steels. Brussels: European Committee for Standardization.

Goldak, J. A. \& Akhlaghi, M. (2005). Computational welding mechanics. Springer Verlag.

Hobbacher, A. (2003). Recommendations for fatigue design of welded joints and components IIW document XIII-1965-03. Technical report, XV-1127-03, Paris.

Michaleris, P. (2011). Courses at pennsylvania state university.

MORFEO (2011). v1.5.2 user's manual. Technical report, Cenaero.

Nussbaumer, A. \& Herion, S. \& Veselcic, M. \& Dietrich, R. (2010). New S-N curves for details in bridges with steel truss tubular superstructure. ISTS 13, Hong Kong.

Radaj, D. (2003, October). Welding residual stresses and distortion. DVS - Verlag.

Schumacher, A. \& Nussbaumer, A. (2006). Experimental study on the fatigue behaviour of welded tubular k-joints for bridges. Engineering structures 28(5), 745-755.
Withers, P. J. (2007, December). Residual stress and its role in failure. Reports on Progress in Physics 70(12), 2211-2264.

Zhao, X. L. \& Herion, S. \& Packer, J. A. \& Puthli, R. S. \& Sedlacek, G. \& Wardenier, J. \& Weynard, K. \& Van Wingerde, A. M. \& Yeomans, N. F. (2000). Design guide for circular and rectangular hollow section joints under fatigue loading (CIDECT, Comité International pour le Développement et l'Etude de la Construction Tubulaire ed.). Number 8 in Construction with hollow steel sections. Köln, Germany: TÜVVerlag. 